\title{
How Much Is Enough? Monte Carlo Simulations of an Oil Stabilization Fund for Nigeria
}

Ulrich Bartsch 



\title{
IMF Working Paper
}

\author{
African Department
}

\section{How Much Is Enough? Monte Carlo Simulations of an Oil Stabilization Fund for Nigeria}

\author{
Prepared by Ulrich Bartsch
}

Authorized for distribution by Roger Nord

June 2006

\begin{abstract}

\section{This Working Paper should not be reported as representing the views of the IMF.}

The views expressed in this Working Paper are those of the author(s) and do not necessarily represent those of the IMF or IMF policy. Working Papers describe research in progress by the author(s) and are published to elicit comments and to further debate.
\end{abstract}

In oil-dependent countries, a major issue is how to stabilize fiscal spending when government revenue fluctuates along with the international price of oil. A stabilization fund would allow the government to pull through an oil price trough and absorb windfall revenue when prices are high. This paper focuses on two key issues. First, the paper proposes to base government spending on moving averages of past oil prices that are shown to behave nearly as a random walk. Second, it uses Monte Carlo simulations of a fiscal policy model to look at the probability that a given level of assets in the stabilization fund is exhausted over a certain number of years. The simulations show that with a fiscal policy based on moving averages over three to five years, a stabilization fund of about 75 percent of 2004 oil revenue would be adequate, which, in Nigeria, would equate to US\$16-18 billion.

JEL Classification Numbers: E27, E63, H62, Q38

Keywords: Oil stabilization fund, oil prices, Monte Carlo simulation

Author(s) E-Mail Address: ubartsch@imf.org 


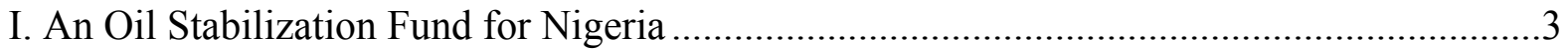

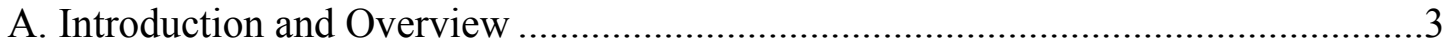

B. Views in the Literature ..............................................................................

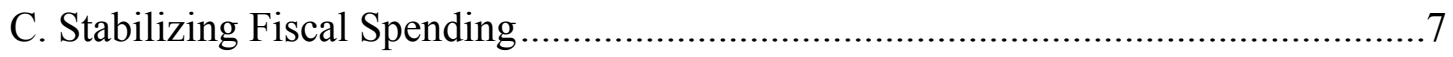

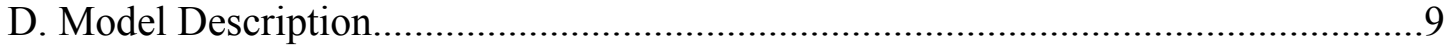

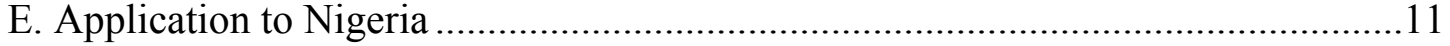

Appendix

Modeling Oil Price Behavior

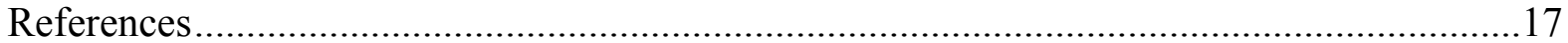

Tables

1. Rott Mean Squared Errors for Price Projections Based on Moving

Averages, 1861-2003 7

2. Changes in Projected Prices, 1861-2003 ............................................................

Figures

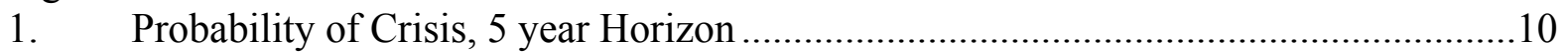

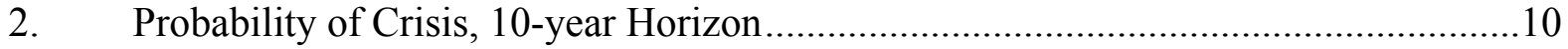

3. Probability of Crisis, 15-year Horizon.............................................................. 10

4. Moving Averages of Recent Oil Prices, Nigeria's Budget Reference Price, 2004-0511

5. Probability of Forced Adjustment in Nigeria, 2005-10 ............................................ 12

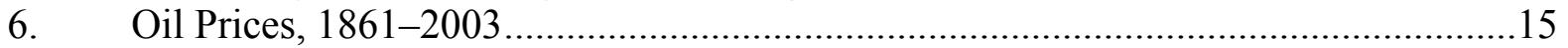

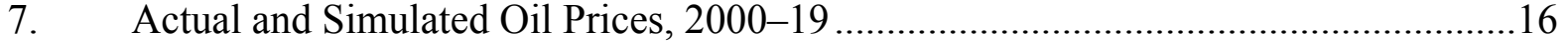




\section{An OIl Stabilization FUnd FOR Nigeria}

\section{A. Introduction and Overview}

In oil-dependent countries, a major issue is how to stabilize fiscal spending when government revenue fluctuates along with the international price of oil. To focus on stabilization, this paper leaves aside the more long-term issue of intergenerational equity and the optimal rate of depletion of an exhaustible resource. ${ }^{1}$ Nigeria is highly dependent on revenue from oil exports, in terms of both its balance of payments and government revenue. Most of Nigeria's oil and gas resources, which are abundant relative to current production levels, are exploited by joint ventures between foreign oil companies and the Nigerian National Petroleum Corporation (NNPC). Domestic income from oil and gas accrues to a very large extent to the government in the form of proceeds from equity oil sales and taxes on private companies. Private income from oil and gas exits Nigeria largely through profit remittances. Government expenditure financed by oil revenue is therefore the only link between international oil prices and the domestic economy. Because international oil prices are volatile, the government's revenue from oil and gas is also volatile. Fiscal spending has been equally volatile, leading to boom-bust cycles, which are partly to blame for Nigeria's disappointing growth performance since independence. ${ }^{2}$

To stabilize fiscal spending, the government must first stabilize the non-oil deficit - that is, the difference between its non-oil revenue and its overall spending. Budgeting for a stable non-oil deficit results in an overall surplus or deficit when oil prices are higher or lower than anticipated. Overall deficits incurred in years with low oil prices need to be financed, and surpluses in years with high oil prices need to be disposed of. Because Nigeria cannot easily borrow in international capital markets, it may not have a source of financing for budget deficits when oil prices are low. A stabilization fund would allow the government to pull through an oil price trough and absorb windfall revenue when prices are high. This paper discusses fiscal policy and the design of a stabilization fund.

The government has two alternatives for holding financial assets in a stabilization fund that provides fiscal liquidity reserves. The assets can either be part of government deposits in the central bank, or be held in a separate foreign currency commercial bank account. ${ }^{3}$ In 2004 , Nigeria deposited its windfall oil revenue in a central bank account, with monetary and

\footnotetext{
${ }^{1}$ The separation of stabilization and long-term maintenance of wealth is possible if we assume that any intergenerational issues are dealt with through government investment inside the country rather than accumulation of financial assets. This requires that the decision on the split between recurrent and investment spending is separable from the decision on overall spending. The country's natural assetthe depleting oil reserve - is therefore replaced with physical assets, such as roads and human capital. Oil production is assumed constant. This paper uses Nigeria as an example, but most of the analysis is equally valid for similar oil-producing countries.

${ }^{2}$ Engel and Meller (1993), Caballero (2000), IMF (2004).

${ }^{3}$ For macroeconomic stabilization purposes, it is important that the financial assets be kept in foreign currency to limit the domestic liquidity injection from oil exports.
} 
exchange rate policy determining the relationship between fiscal deposits in the central bank and foreign reserves held by the central bank. Obviously, government deposits would closely mirror foreign reserves taking into account the import content of government spending to avoid liquidity injection or withdrawal in line with government deposit drawdown or buildup.

This paper focuses on two key issues. First, given uncertainty of future oil prices, how much of its revenues should the Nigerian government spend? Fiscal policy design would be relatively straightforward if oil prices fluctuated in a reasonably short time around a long-term average, in which case the government should spend its mean expected oil revenue while maintaining a precautionary liquidity reserve for low-price periods. But because oil prices show very weak mean reversion (see Appendix) — that is, oil price shocks are of long duration and the long-term average oil price is of little use for policymaking - the government has more difficulty determining its fiscal policy.

The paper proposes that Nigeria use moving averages of past oil prices to estimate its future revenue and that it base its spending on this expected revenue. This solution strikes a balance between using this year's price to estimate next year's revenue, which would lead to the smallest forecast error because of the statistical properties of oil prices - such a policy would transmit oil price volatility to the economy - and using a long-term average price, which could lead to large and persistent surpluses and deficits because of the slow mean reversion of oil prices. Given the trade-off between stability of spending and over- or under-shooting actual oil revenue, this paper argues that Nigeria should base spending on revenue projected on the basis of moving averages of oil prices over three to five years.

Irrespective of which method the government uses to guide its spending, any fiscal policy would run up against the difference between budgeted oil revenue and realized oil revenue. The question that arises about the design of a stabilization fund is, therefore, how much is enough: what level of assets should the government have in a stabilization fund to give assurance that it can maintain a stable fiscal policy?

This paper uses repeated simulations of a numerical fiscal policy model with randomly generated parameters (Monte Carlo simulations) to look at the probability that a given level of assets in the stabilization fund is exhausted over a certain number of years. The model presented in Section D is based on randomly generated oil prices, where the data-generation process was estimated on the basis of real oil prices over the period 1861-2004 (see Appendix). The simulations provide probabilities of the government's encountering a budget crisis when, because of a liquidity constraint, it cannot spend the amounts budgeted. The simulations show that with a fiscal policy based on moving averages over three to five years, a stabilization fund of about 75 percent of 2004 oil revenue would be adequate. Section E derives the implications of the Monte Carlo simulations for fiscal policy in Nigeria and concludes that fiscal liquidity reserves of US\$16-18 billion would be adequate. 


\section{B. Views in the Literature}

The literature on oil-dependent countries and revenue volatility clearly points out that delinking spending from revenue is important to promote macroeconomic stability and create an enabling environment for growth. ${ }^{4}$ Two possibilities for delinking are discussed: on the one hand, selfinsurance through diversification of revenue and stabilization funds and on the other, transfer of risk to international capital markets (hedging). ${ }^{5}$ Diversification may take a long time and may not be compatible with a country's comparative advantage. Hedging may be constrained by the limitations of futures markets: liquidity in long-dated instruments with maturities of more than one year is still limited (compared with Nigeria's production volumes). In addition, hedging requires a high level of skill and oversight, and its political pay-offs may be very asymmetrical: the minister of finance may gain little political capital from the stabilization of revenue when oil prices fall, but may face severe criticism when prices rise and the country does not benefit from the upswing. Doubts over Nigeria's creditworthiness may also make it difficult for the government to participate effectively in futures markets and would prevent it from borrowing when oil prices fell. ${ }^{6}$

Countries whose economies depend on natural resources have had mixed experiences with stabilization funds. Apart from Norway and Alaska, ${ }^{7}$ funds have usually not fulfilled their creators' expectations. ${ }^{8}$ In several cases, the countries adopted rigid rules for depositing assets into and withdrawing them from the fund, which meant that they accumulated assets while budget deficits required financing, either domestic or external. Often, funds could not withstand the political pressure to use assets when natural resource prices were higher than their historical averages. If depleted, stabilization funds could not fulfill their role when resource prices slumped. In several countries, funds also developed lives of their own taking over budgetary functions by financing "national priority" investment projects.

The literature therefore provides clear guidance on the design of such funds. Most importantly, experience has shown that effective stabilization funds are fully integrated in the budget and are

\footnotetext{
${ }^{4}$ See for example Engel and Meller (1993), Hausmann and Rigobon (2003), and Caballero (2000).

${ }^{5}$ Arrau and Claessens (1992), Valdès (1993), Daniel (2003). Interestingly, a third option to reduce revenue volatility does not seem to attract much attention: governments could design fiscal regimes for private oil companies such that the companies rather than the governments shoulder more of the price risk.

${ }^{6}$ In principle, governments can print money when resource revenue falls short of expectations. Printing money would not, of course, enable the government to buy foreign goods and would also trigger domestic inflation and currency depreciation. After creating a short-lived illusion, the government would be worse off than before. This option for dealing with revenue uncertainty is therefore not discussed in the literature.

${ }^{7}$ It should be noted that funds in the U.S. state of Alaska, and in Norway and some other countries, including Kuwait and Oman, have been set up to hold oil revenue for future generations to ensure intergenerational equity.

${ }^{8}$ See Davis and others (2001).
} 
not based on specific rules that determine the accumulation of assets in or their withdrawal from the fund. Instead, changes in fund assets are derived from the difference between oil revenue and the non-oil primary balance. The question therefore is how to determine the level of expenditure.

Assuming that holding assets in a stabilization fund is costly (the interest earned on the assets is less than the return the government could derive from an alternative use of those assets), the government maximizes utility, which it derives from spending, under uncertainty over income and facing a borrowing constraint. While the maximization problem is straightforward, its analytical solution is not.

Monte Carlo simulations can indicate the level of assets the government should hold in a stabilization fund. The model presented in Arrau and Claessens (1992) derives precautionary savings from utility maximization over two periods, with each period representing one month. Using plausible parameters for risk aversion and interest rates, the Monte Carlo simulations show that about 40 percent of a government's monthly earnings would be held in a stabilization fund. Their analysis does not explicitly impose fiscal stabilization; rather fiscal stabilization is a result of spending and saving decisions in each period. The spending path in the simulations is less volatile than revenue, showing the extent to which the stabilization fund is successful.

This paper is not based on an explicit maximization model, but instead imposes a simple fiscal policy rule from the outset to stabilize the non-oil primary balance and takes into account a longer time horizon. Rather than determining the optimal level of stabilization and fund assets, it focuses on making explicit the trade-offs between stabilization and costs and on providing a more intuitive approach to determine how much is enough. The results compare well with those of Arrau and Claessens: although it is proposed here that a stabilization fund should have a higher level of assets than what they derive, the path of spending is also more stable.

The literature on stabilization funds makes little mention of the relationship between the government's liquidity and the central bank's international reserves. Research on reserve adequacy has not examined stabilizing fiscal spending when government revenue depends on volatile international prices. ${ }^{9}$ Studies on reserve adequacy in the 1960 s and 1970s focused mainly on the current account and yielded the rule of thumb that reserves should cover three months of imports. Following the financial crises of the late 1990s, the literature focused on the risk of a currency crisis stemming from sudden capital flow reversals. It is based on the Baumol-Tobin inventory model with fixed costs of depleting and replenishing reserves and has yielded a new rule of thumb, coined by Federal Reserve Chairman Alan Greenspan (1999), that reserves should fully cover short-term foreign liabilities. ${ }^{10}$

\footnotetext{
${ }^{9}$ See, for example, Frenkel and Jovanovic (1981) and Flood and Marion (2002) for a recent review.

${ }^{10}$ Jeanne and Rancière (2005) develop a maximization model with costs of reserves (interest rate differential) and risk aversion given a probability of facing a financial crisis. The results support the so-called "Greenspan rule."
} 


\section{Stabilizing Fiscal Spending}

Policymakers need to determine what level of non-oil deficit can be maintained over time. As discussed in the appendix, however, a sizable body of literature looking into the behavior of oil prices concludes that they are subject to large shocks and have a very weak tendency to revert to a mean. For practical purposes, they follow a random walk, which means today's price is the best predictor of tomorrow's, and no medium- or long-term mean can be determined to anchor government spending. A fiscal policy aimed at spending the revenue expected on the basis of a long-term oil price would, at some point, lead to either large deficits, the depletion of stabilization assets, and the accumulation of debt or to the accumulation of very large financial assets, which would be hard to justify in poor countries.

Because year-to-year oil price volatility can be quite large, a fiscal policy based on oil prices in the previous year would transmit oil price swings to the economy with a one-year lag. The resulting "boom-bust" cycles have been observed in many oil-dependent countries in the past. To avoid such cycles, fiscal spending should instead be anchored on a slow-moving, mediumterm budget oil price. ${ }^{11} \mathrm{~A}$ trade-off exists between fiscal stabilization and the errors made in projecting oil prices: the more fiscal spending is delinked from oil revenue, the higher the likelihood of fiscal deficits and surpluses. This section illuminates the trade-off by showing forecasting errors and forecast volatility for different degrees of stabilization.

\section{Forecasting errors}

A moving average of past oil prices provides a possible medium-term anchor for fiscal policy. Table 1 compares different time spans over which the moving average can be determined. It shows the errors that would have been made in projecting oil prices using moving averages over one to nine years. ${ }^{12}$ For example, projections based on a moving average over the preceding four years would have diverged from actual prices by an average of US\$10.2 per barrel for the period 1861-2003.

Table 1. Root Mean Squared Errors for Price Projections Based on Moving Averages, 1861-2003

\begin{tabular}{|c|c|c|c|c|c|c|c|c|c|}
\hline & \multicolumn{9}{|c|}{ Averaging period, number of years } \\
\hline & 1 & 2 & 3 & 4 & 5 & 6 & 7 & 8 & 9 \\
\hline \multicolumn{10}{|c|}{ Errors (in U.S. dollars) } \\
\hline Full sample & 9.1 & 10.9 & 11.5 & 10.2 & 9.7 & 9.9 & 10.3 & 10.9 & 11.7 \\
\hline $1970-2003$ & 10.6 & 12.1 & 13.5 & 14.9 & 14.9 & 15.9 & 17.3 & 18.5 & 19.8 \\
\hline
\end{tabular}

Sources: BP Statistical Review of World Energy, author's calculations.

\footnotetext{
${ }^{11}$ In Nigeria, fiscal policy is based on an oil price rule, that is, it targets a balanced budget at the budget oil price. Actual oil prices higher or lower than the budget oil price lead to surpluses or deficits. This policy is equivalent to choosing a stable non-oil balance: in the absence of the oil price rule, the budget office would still need to determine expected revenue under some assumed oil price path, and then translate the revenue into a feasible non-oil balance path.

${ }^{12}$ The table calculates the root of the mean of squared differences between moving averages over one to nine years and actual prices.
} 
The same projections over the period 1970-2003 would have missed actual prices by an average of US\$14.9 per barrel. ${ }^{13}$ The errors are smallest in the first column, that is, when the previous year is used to project prices. The longer the averaging period, the greater the error, at least in the volatile world following the nationalizations and ascent of the Organization of Petroleum Exporting Countries (OPEC) in the 1970s. This finding is consistent with the nearrandom-walk properties of oil prices: last year's price is the best predictor of today's, as shown in the first column of Table 1.

\section{Forecast volatility}

If, however, the random walk price rule - this year's price is used to project next year's revenue - were followed, the volatility of fiscal spending would be high. Table 2 shows average year-to-year changes in oil prices, projected by using moving averages.

Table 2. Changes in Projected Prices, 1861-2003

\begin{tabular}{|c|c|c|c|c|c|c|c|c|c|c|}
\hline & & \multicolumn{9}{|c|}{ Averaging period, number of years } \\
\hline & & 1 & 2 & 3 & 4 & 5 & 6 & 7 & 8 & 9 \\
\hline \multicolumn{11}{|c|}{ Change from previous year (in percent of previous year's price) } \\
\hline \multirow[t]{2}{*}{ Full sa: } & Mean & 20.3 & 14.6 & 10.9 & 8.1 & 6.5 & 6.0 & 5.8 & 5.5 & 5.2 \\
\hline & Standard deviation & 27.9 & 20.1 & 14.4 & 9.6 & 7.8 & 7.0 & 6.4 & 6.1 & 5.8 \\
\hline \multirow[t]{2}{*}{$1970-2$} & Mean & 24.8 & 17.8 & 14.8 & 12.9 & 11.2 & 10.7 & 10.3 & 9.7 & 9.1 \\
\hline & Standard deviation & 40.1 & 24.5 & 17.5 & 15.0 & 12.7 & 11.3 & 10.3 & 9.5 & 8.9 \\
\hline
\end{tabular}

Sources: BP Statistical Review of World Energy, British Petroleum; author's calculations.

The table shows that the prices projected using, say, a four-year moving average change by 8.1 percent of the previous year's price, on average, with a standard deviation of 9.6 percent. Obviously, the longer the averaging period the lower the volatility of projected prices, but averaging beyond about five years does not seem to lead to substantial reductions in volatility. The higher oil price volatility since the 1970s is reflected in Table 2 in the higher mean and standard deviation of changes compared to the full sample period 1861-2003.

In conclusion, forecasting errors and forecast volatility suggest that fiscal spending guided by an oil price determined as a moving average of three to five years provides an adequate level of stabilization, while forecasting errors would be relatively small. ${ }^{14,15}$

\footnotetext{
${ }^{13}$ Prices have become more volatile since the 1970 s.

${ }^{14}$ This is a rather casual, rule-of-thumb approach. One could instead envisage a formal maximization model to choose the optimum level of stabilization given the costs of holding more assets in a stabilization fund. Such a model, while theoretically straightforward, would be very hard to formulate empirically because of the difficulties involved in determining costs of adjustment of fiscal spending.

${ }^{15}$ Venezuela and Chile determined deposits in their stabilization funds on the basis of moving averages of commodity prices, see Arrau and Claessens (1992), Claessens and Varangis (1994), Davis and others (2001). It should be noted, however, that in times of rapidly rising oil prices the moving averages as proposed here could still lead to an increase in government spending that could be considered excessive relative to absorptive and administrative capacity constraints. The moving-average rule would then have to be lengthened to give time to build capacity.
} 


\section{Model Description}

Randomly generated oil prices are fed into a fiscal policy model to produce changes in stabilization fund assets over time. The probability that stabilization fund assets are exhausted in any year during the simulation horizon is then computed over a large number of model runs.

\section{The assumptions in detail are as follows:}

Based on regression results, oil prices are modeled using an AR(1) process in logarithms. The current oil price depends on last year's price and a random variable,

$$
P_{t}=\alpha+\beta P_{t-1}+\varepsilon_{t}
$$

where $\alpha=0.802$, and $\beta=0.703$, as shown in the appendix. Time series of 5,10 , or 15 years' duration are produced 5,000 times starting with actual 2004 prices of oil. Government spending $E_{t}$ is set equal to projected non-oil revenue, $\hat{R}_{t}^{\text {non-oil }}$, plus oil revenue, $\hat{R}_{t}^{\text {oil }}$, at the projected oil price: ${ }^{16}$

$$
E_{t}=\hat{R}_{t}^{\text {non-oil }}+\hat{R}_{t}^{o i l}
$$

Projected oil revenue is modeled as the taxes paid on production value, which is calculated as quantity, $Q_{t}$, times projected price, $\hat{P}_{t}$ (where quantity is assumed to be constant): ${ }^{17}$

$$
\hat{R}_{t}^{\text {oil }}=\tau \hat{P}_{t} Q_{t}
$$

The projected oil price, or budget reference price, for each year is set equal to the preceding year's price ( $M A 1)$, or moving averages over the preceding three, five, or seven years ( $M A$ 3-7). In each year, the randomly generated oil price leads to oil revenue that is higher or lower than projected, and, therefore, an overall surplus or deficit. Assets in the stabilization fund at the end of each year, $A_{t}$, rise or fall with the budget balance:

$$
A_{t}=A_{t-1}+\left(R_{t}^{o i l}-\hat{R}_{t}^{o i l}\right) \text {. }
$$

The analysis is performed for time periods of 5, 10, and 15 years. The model has been normalized using $t_{o}=2004$ oil revenue, and initial stabilization fund assets, deposits, and

\footnotetext{
${ }^{16}$ Non-oil revenue is assumed to be predictable and independent of spending decisions.

${ }^{17}$ Stochastic development of production capacity would complicate the analysis. Risks would obviously increase. Stochastic development also assumes that taxes are a constant fraction of production value, which is a permissible approximation only if tax-deductible production expenses are small relative to production value.
} 
withdrawals are expressed in percent of $t_{o}$ revenue. ${ }^{18}$ The model calculates the probability that stabilization fund assets are exhausted in any year during the simulation horizons.

The simulation results show that the probability of asset exhaustion rises with lower initial assets in the stabilization fund, a longer simulation horizon, and more stable fiscal spending or a longer moving average (Figures 1-3). The fewer the assets in the fund initially, the greater the probability that they will be exhausted during a period of low oil prices. Because of the cumulative effect of deficits, the probability of asset exhaustion rises with the length of the simulation period. And because a longer moving average increases the divergence between the budgeted and the realized price, a more stable fiscal policy requires a higher level of assets. These results are in line with the discussion in the subsection on forecasting errors and the appendix.

If initial asset levels are low or zero, however, fiscal smoothing through the use of moving averages reduces the risk of a crisis, the opposite of what we observe when initial assets are moderate to high. The result is due to the slow change in fiscal policy that results from using moving averages, which allows some assets to build up in "good" years when there had been no assets before. As a result, "bad" years later on in the simulation period can be smoothed over. In contrast, "bad" years early on lead to
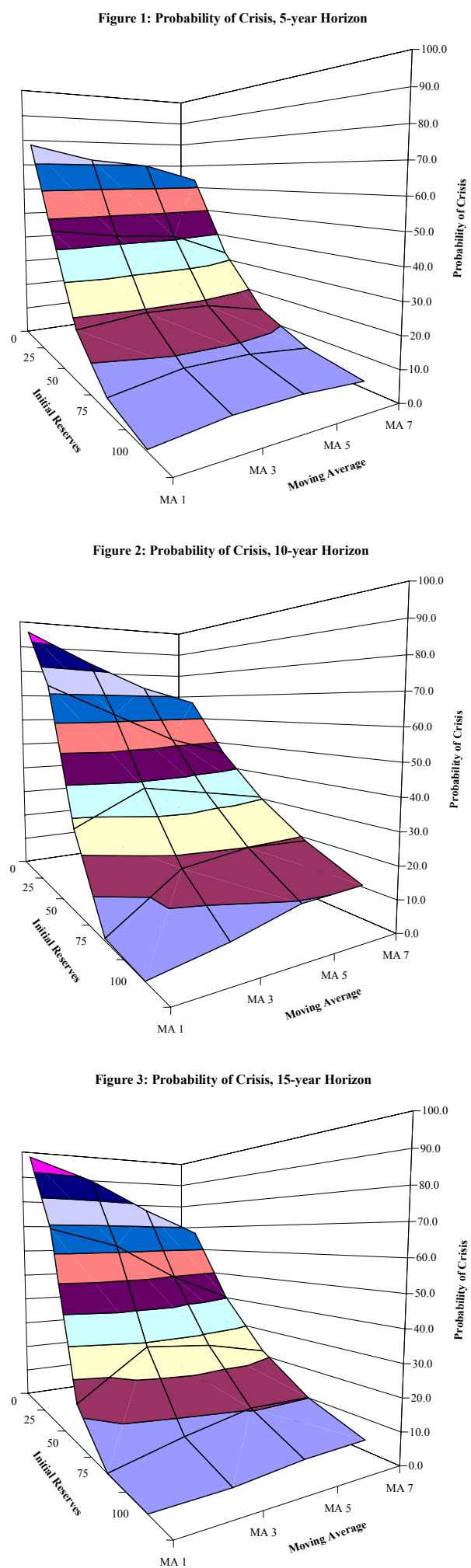

${ }^{18}$ Starting with a balanced budget in 2004, the model produces data denominated by the non-oil deficit. It should be noted that the model uses real U.S. dollars for all variables. It does not take into account exchange rate and dollar deflator feedback effects of oil prices. 
a crisis no matter which smoothing strategy is used. When using last year's oil prices (moving average of one period), fiscal policy instead allows little room to build up assets, and short "bad" spells lead to a crisis irrespective of when they occur. On balance, therefore, using a moving average over longer periods reduces fiscal vulnerability to "bad" spells, when the fund has few initial assets. Alternatively, a government can base its fiscal policy on deliberately low oil prices to attempt to build assets rapidly until it accumulates enough to move to fiscal policy based on a three-to-five-year moving average.

In conclusion, the analysis shows that governments should best pursue a prudent and stable fiscal policy aimed at building up financial assets in a stabilization fund if initial assets are very low. Only then should they try to base their spending on a more realistic projection of oil revenue while keeping in mind the need for stabilization, for example, by basing spending on a three-year moving average of oil prices. Inspection of the simulation results in Figures 1-3 shows that stabilization fund asset levels of about 75 percent of 2004 oil revenue reduce the probability of forced adjustment to below 20 percent in all three scenarios which could be considered adequate insurance against oil revenue shortfalls.

\section{E. Application to Nigeria}

Nigeria's federal government followed a fiscal rule for the first time in $2004 .{ }^{19}$ It deposited in the central bank the oil revenue it received from prices above US\$25 per barrel in 2004, and above US\$30 per barrel in 2005. The federal authorities obtained informal cooperation from state and local governments, which then also deposited their share of windfall revenue. The federal authorities are now proposing a fiscal responsibility bill that entails formally adopting a fiscal rule that would be binding on all three tiers of government and creating a stabilization fund.

Nigeria's federal government budget for 2005 is based on a budget reference price of US\$30 per barrel. Although the process that led parliament to choose this price is not clear, it is consistent with a moving average of oil prices over the past three years. In 2004, the budget reference price was US $\$ 25$ per barrel, consistent with a moving average over four years (Figure 4). ${ }^{20}$ These prices are

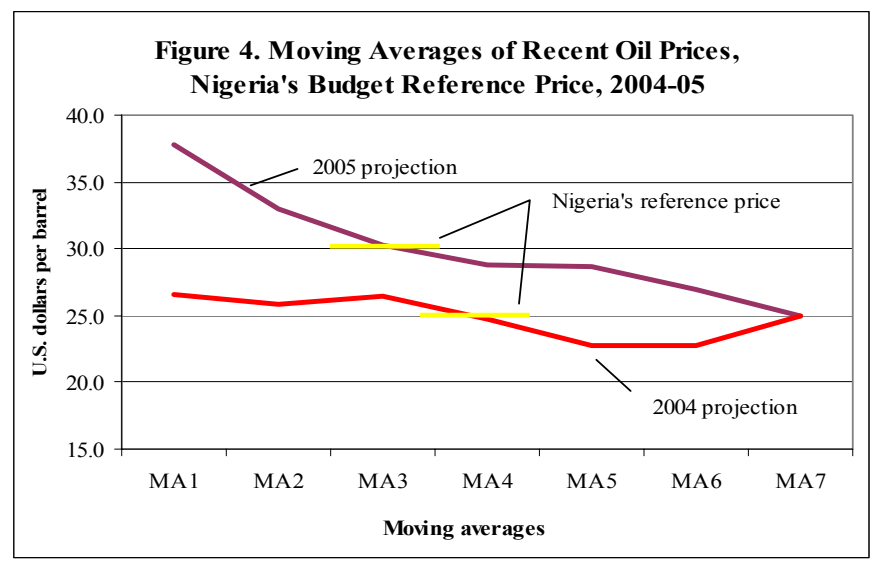

${ }^{19}$ The framework for reference budgeting and saving surpluses has existed for some time, but spending pressures usually led to a supplementary budget being prepared to use any windfall oil revenue right away.

${ }^{20}$ In 2004, the federal government targeted a deficit at the reference price to be financed from repatriated looted funds, privatization receipts, and domestic borrowing. In 2005, all three levels of government are targeting deficits to be financed with about one-half of the windfall revenue deposits

(continued) 
well below price projections at the time of budget formulation, and actual prices. The rationale is that the government aims to stabilize the non-oil primary balance and build financial assets.

The Monte Carlo simulation framework can be used to calculate the probability that the Nigerian government will exhaust its financial assets in the medium term (five years). ${ }^{21} \mathrm{We}$ calculate three different fiscal policy rule scenarios: in the first, we assume that the authorities use a three-year moving average to determine the budget reference oil price and fiscal spending and that initial stabilization fund assets are equal to the saved windfall oil revenue earnings of 2004 (of US\$6 billion); the authorities aim at a balanced budget. ${ }^{22}$ In the second scenario, the authorities plan for a federal government deficit of 3 percent of non-oil GDP at the same reference price in line with recent practice. In the third scenario, they follow their medium-term fiscal strategy, as expressed in the NEEDS, and project a 3 percent deficit with the price of oil at US\$27 per barrel starting in $2006 .^{23}$

The Nigerian government has a 35 percent chance of depleting its assets within the next five years if it pursues a balanced budget policy at the reference oil price determined on the basis of a three-year moving average ("balanced budget" in Figure 5). The simulations that were performed in percent of 2004 oil earnings are here converted back into U.S. dollar amounts. Nigeria's 2004 oil revenue is about US\$21 billion, and initial assets in the stabilization fund amount to US\$6

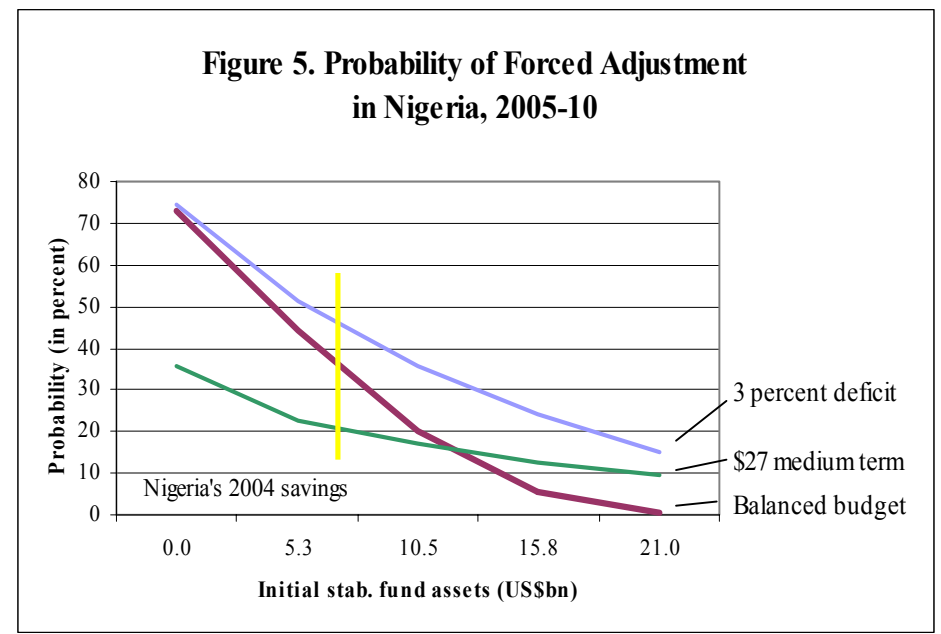
billion fiscal savings in 2004 (vertical line in Figure 5).

of 2004. Consolidated spending in 2004 was therefore more in line with the revenue Nigeria would have received had the oil price been US\$28 per barrel, and 2005 spending is projected to be in line with about US\$33 per barrel.

${ }^{21}$ It should be noted, however, that the results will overstate Nigeria's risks because production increases that are highly likely to occur over the next five to ten years are not taken into account.

${ }^{22}$ While the country had net foreign reserves of US\$17 billion at end-2004, government deposits in the blocked central bank account for windfall oil revenue amounted to US\$6 billion.

${ }^{23}$ While the Nigerian government is discussing a debt buy back with its Paris Club creditors, the analysis in this chapter takes the debt as a given; it is neither repaid using financial assets, nor can the government borrow more domestically or abroad. 
If the authorities continue to target a federal government deficit of 3 percent of GDP at the reference price, the probability that they will be forced to adjust their fiscal policy stance within the next five years rises to about 45 percent (Figure 5, "3 percent deficit"). Finally, the announced medium-term fiscal stance based on a fixed reference price of US\$27 per barrel and a federal deficit of 3 percent of GDP brings down the risk of forced adjustment to 20 percent. This result follows from a relatively low medium-term reference price compared with the 2004 actual oil price of US\$38 per barrel (Figure 5, \$27 medium-term). ${ }^{24}$

In conclusion, the results show that the authorities' medium-term strategy, which is based on a reference oil price of US\$27 per barrel, is consistent with ensuring fiscal stability over the medium term and with increasing financial assets that provide further insurance against forced adjustment later on. They also show that the oil revenue savings currently in the dedicated central bank accounts are too low to suggest that the government should target spending on the basis of realistically projected oil prices or a moving average of past prices. The government would run a high risk of being forced to abandon its intended fiscal stance. Assets of US \$16-18 billion would reduce the probability of crisis within the next five years to below 20 percent, depending on the fiscal policy rule.

The authorities' medium-term fiscal goals (US\$27 per barrel and 3 percent deficit) aim at increasing financial assets to more than the current US\$6 billion. The spending targeted in the 2005 budget exceeds what would be targeted in this medium-term fiscal strategy because envisaged spending is more in line with a price of US\$33 per barrel. However, the reference price is still below the oil price of 2005 (US\$55 per barrel), while the 2004 oil price, seen as the best predictor of the 2005 price under the random walk hypothesis, was US\$38 per barrel. The budget is consistent with accumulating assets that can be used to stabilize fiscal spending in the future.

\footnotetext{
${ }^{24}$ If, indeed, the 2004 price is used as the reference price and the authorities target a balanced budget at this price, the probability of asset exhaustion rises to 43 percent.
} 


\section{Modeling Oil Price Behavior}

Oil prices over the last century have exhibited considerable volatility, which was eclipsed by dramatic changes (upward in 1973 and 1979, and downward in 1985), as well as sudden spikes (in 1990 and possibly 2004-05). This appendix looks at the statistical properties of past oil prices that have been used in the Monte Carlo simulations of the fiscal policy model in the main text. We reestimate some of the results of Pindyck (1999) and Engel and Valdès (2000), who argue that past oil prices can best be described by a simple autoregressive process. ${ }^{25}$ The generic form of these models links today's price to a trend, at least one lagged price, and a "white noise" random variable.

$$
P_{t}=\alpha_{t}+\delta_{t} \operatorname{Trend}_{t}+\rho_{t} P_{t-1}+\varepsilon_{t}
$$

Simple tests show that lags of more than one period are not relevant. Engel and Valdès test the forecasting ability of different oil price determination models, including random walk and autoregressive models. They estimate each model repeatedly using quarterly data that ended in the second quarter of the years 1994 to 1998 and forecast from the estimating sample. They then compute the root mean square error using forecast errors at horizons of one and two years.

They conclude that none of the models provides superior forecasting ability to a simple random walk without drift; that is, i.e. $\alpha_{t}$ is zero, the coefficient of the trend variable, $\delta_{t}$, is zero, and $\rho_{t}$ is unity. However, statistical tests confirm the significance of drift in past oil prices, with $\alpha_{t}$ different from zero, and the coefficient on the lagged oil price different from unity, as shown below.

Looking at real oil prices over the past 140 years (Figure 6), one wonders whether the large variations are indicative of structural changes in the oil market. In fact, the creation of OPEC, and the changes in its market management behavior over time, would lend support to the hypothesis that structural changes have occurred several times during the course of oil price history. We can test the validity of this hypothesis using dummy variables.

${ }^{25}$ All tests are performed using logs of oil prices. 
Figure 6: Oil Prices, 1861-2003

(In logs of real oil prices)

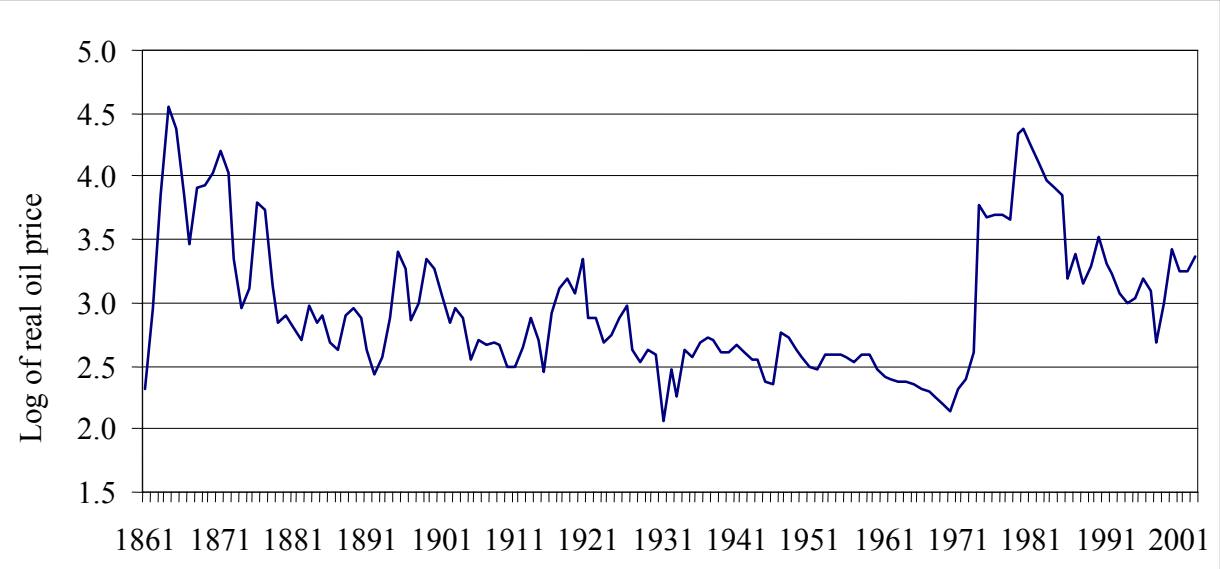

Simple unit root tests (augmented Dickey-Fuller, ADF) on the log of oil prices between 1861 and 2003 have been performed with different dummy variables: D1 for the period 1974 to 2003, D2 for 1979-03, and D3 for 1974-85. ${ }^{26}$ The tests strongly support the inclusion of a one-year lag of the oil price in a regression model, but the dummies all come short of significance at the 5 percent level, although D3 may be significant at the 10 percent level. In a linear, ordinary least squares AR(1) regression, D3 is significant at the 5 percent level and its inclusion in the model improves its fit.

In addition, market volatility seems to have been very large during the early years shown in the series. One could easily argue that, until about the turn of the twentieth century, oil was an exotic commodity, and markets were thin and did not function well. In fact, when the period prior to 1904 was left out, model fit improved. ${ }^{27}$ Therefore, the best-fit model of oil price behavior was estimated as shown below (t-values in parentheses). ${ }^{28}$

$$
P_{t}=\underset{(5.16)}{0.8015}+0.4422 \mathrm{D} 3+0.7029 P_{t-1}+\varepsilon_{t}
$$

\footnotetext{
${ }^{26}$ Prices started rising in 1971, but the big price increase followed the imposition of supply restrictions by Saudi Arabia during October 1973. A high point was reached in 1980, but the dramatic end to the "OPEC years" came with the decision by Saudi Arabia to move to netback pricing in the fall of 1985.

${ }^{27}$ The choice of 1904 was arbitrary, giving 100 observations for the regression.

${ }^{28}$ Other descriptive statistics:

$\begin{array}{lllll}\text { Sigma } & 0.201423 & \text { RSS } & 3.93539512 & \\ \mathrm{R}^{\wedge} 2 & 0.848708 & \mathrm{~F}(2,97)= & 272.1\lceil 0.000\rceil^{* *} & \\ \text { Log-likelihood } & 19.8641 & \mathrm{DW} & 1.9 & \\ \text { No. of observations } & 100 & \text { No. of parameters } & 3 & \text { (Concluded) } \\ \text { Mean }(\ln P) & 2.8666 & \text { var(lnP) } & 0.260119 & \end{array}$
}


The calculated standard deviation of the regression was used to produce 5,000 series of 15 random error terms. The random terms were then plugged into the regression equation to produce 5,000 oil price series of 15 years' duration (omitting the dummy term), and the resulting logs were converted into real oil prices. Real oil prices were used in the fiscal policy model to calculate probabilities of stabilization fund exhaustion.

Figure 7: Actual and Simulated Oil Prices, 2000-19

(In U.S. dollars per barrel, in constant 2002 U.S. dollars)

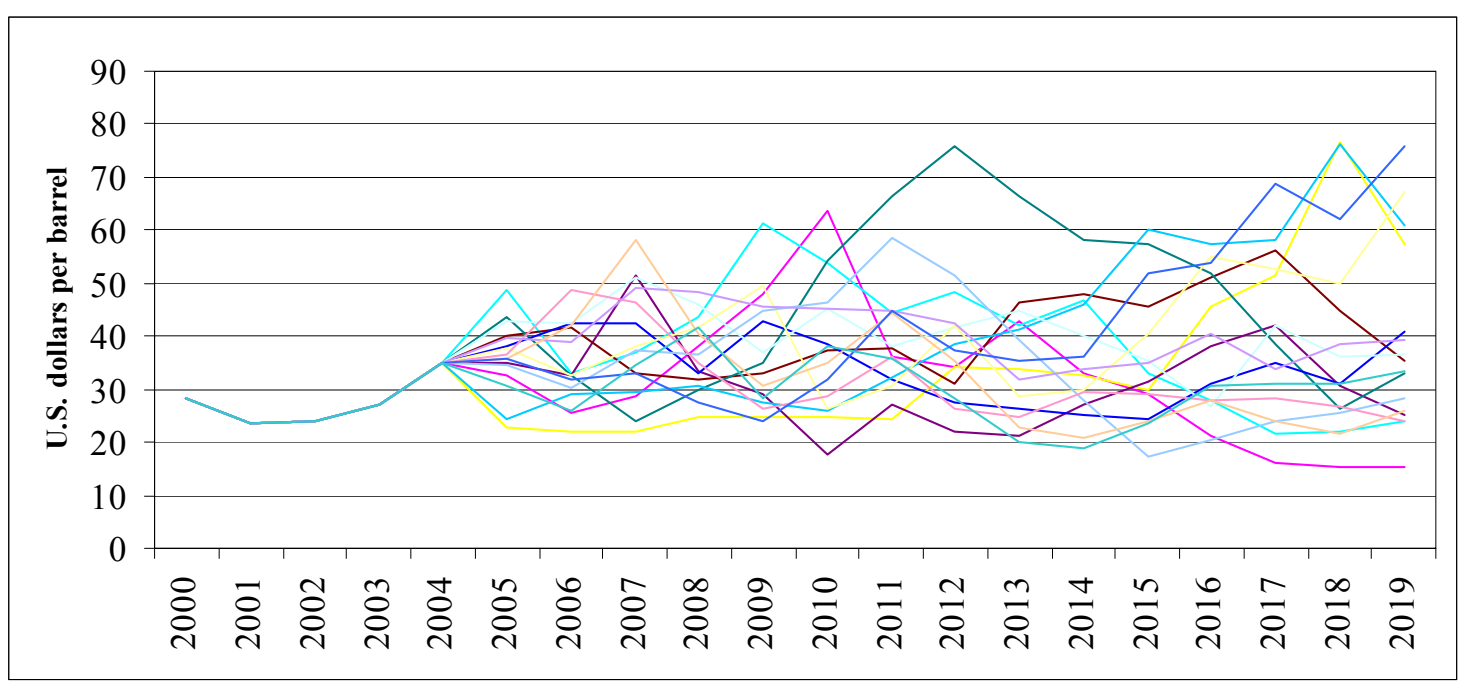




\section{References}

Arrau, Patricio, and Stijn Claessens, 1992, "Commodity Stabilization Funds," Policy Research Working Paper No. 835 (Washington: World Bank.)

Caballero, Ricardo, 2000, "Macroeconomic Volatility in Latin America: A View and Three Case Studies," NBER Working Paper No. 7782 (Cambridge, Massachusetts: National Bureau of Economic Research)

Claessens, Stijn and Panos Varangis, 1994, “Oil Price Instability, Hedging, and an Oil Stabilization Fund: The Case of Venezuela," Research Working Paper No. 1290 (Washington: World Bank).

Daniel, James, 2001, “Hedging Government Oil Price Risk,” IMF Working Paper 01/185 (Washington: International Monetary Fund)

Davis, Jeffrey, Rolando Ossowski, James Daniel, and Steven Barnett, 2001, "Stabilization and Savings Funds for Nonrenewable Resources," IMF Occasional Paper No. 205 (Washington: International Monetary Fund).

Deaton, Angus, 1991, "Saving and Liquidity Constraints," Econometrica, Vol. 59 (September), pp. 1221-48.

Engel, Eduardo, and Rodrigo Valdès, 2000, “Optimal Fiscal Strategy for Oil-Exporting Countries,” IMF Working Paper 00/118 (Washington: International Monetary Fund).

Engel, Eduardo, and Patricio Meller, 1993, External Shocks and Stabilization Mechanisms (Washington: Inter-American Development Bank).

Flood, Robert, and Nancy Marion, 2002, "Holding International Reserves in an Era of High Capital Mobility,” IMF Working Paper 02/62 (Washington: International Monetary Fund).

Greenspan, Alan, 1999, "Currency Reserves and Debt," remarks before the World Bank Conference on Recent Trends in Reserves Management, Washington, DC, April 29.

International Monetary Fund 2004, Nigeria-Selected Issues Papers and Statistical Appendix, Country Report 04/242, Washington.

Olivier, Jeanne, and Romain Rancière, 2005, "The Optimal Level of International Reserves for Emerging Market Countries: Formulas and Applications," No. 39 (May); pp. 1-34/

Pindyck, Robert, 1999, “The Long-Run Evolution of Energy Prices,” Energy Journal, Vol. 20, pp. 1-27. 